\title{
The Operation Mechanism, Realistic Dilemma and Improvement Path of Local Government Purchasing Public Performance
}

\author{
Yurun Gong* \\ School Of Public Administration and Humanities \\ Dalian Maritime University \\ Dalian City, China
}

\author{
Jin Song \\ School Of Public Administration and Humanities \\ Dalian Maritime University \\ Dalian City, China
}

\begin{abstract}
This paper finds that the operating mechanisms for local governments to purchase public performances mainly include four aspects: public performance market-building mechanism, budget preparation mechanism, procurement execution mechanism, supervision, and restriction mechanism. However, there emerge problems such as insufficient purchasing scale, insufficient market competition. Therefore, this paper will analyze the operating mechanisms of the local government purchasing public performances, interpret its realistic difficulties, and explore its future development path.
\end{abstract}

Keywords-Local government; Government purchase; Public performances; public culture service

\section{INTRODUCTION}

With the development of our country's social economy, the demand of urban and rural residents for recreational products is also showing a significant upward trend and the proportion of recreational consumption in China's residents' consumption is steadily increasing. In 2017, China's performing arts groups performed 2.937 million performances, an increase of $27.4 \%$ over the previous year. China's commercial market for performing arts is showing signs of vigorous development [1].

However, the scale of public performances purchased by the Chinese government is still relatively small. In 2017, the total number of public performances purchased by the government was 160700, accounting for only about $5 \%$. Therefore, in order to further protect citizens' cultural rights and interests, especially to meet the entertainment needs of low-income groups, governments at all levels need to further increase their purchasing power for public performances.

It has a long history in developed countries in Europe and America where the cultural market is relatively mature. For example, the United States has gradually formed a public performance management mode characterized by "people-topeople dominance" and "award instead of compensation" through long-term practice. Under this model, the federal government does not set up an administrative department to provide public performance services, but hands over some

This paper is a phased achievement of The youth project of social science foundation of Liaoning Province "study on the decision mechanism and improvement path of law enforcement intensity of local environmental regulation departments" (project no. L17CG011), and Key project of social science foundation of Liaoning Province in 2018 "research on development issues of producer services in Liaoning Province based on Bohai economic circle" (project no. : L18AJY010) coordination and funding functions to non-governmental organizations for indirect management [2]. For example, the National Endowment for the Humanities holds quarterly hearing sessions to review public cultural projects (including public performances) that apply for financial assistance and to evaluate them according to the requirements of the 1965 National Arts and Humanities Foundation Act [3]

Public performances purchased by local governments are quite different from those purchased by the central government. The public performances purchased by the central cultural department without exception have strong political, demonstrative and international exchange characteristics, and high demands on levels, specifications, and artistic level Therefore, the purchase of public performances by the local government refers to the purchase of regional cultural performances by the local government to meet the spiritual and cultural needs of the local residents, through the market competition mechanism, outsourcing contracts are signed with social performance agencies in the form of bidding, negotiation, subsidies and so on, and by transferring financial funds to provide residents with regional cultural performances for free.

\section{OPERATING MECHANISM}

"Mechanism" originally refers to the structure and operation principle of the machine, extends to the operation mechanism of local government purchasing public performance services, it refers to a unified whole organically linked by a series of specific operation links, policies and regulations, systems, and norms, and is a market-oriented operation mechanism that introduces a competitive system. Specifically, it mainly includes five sub-mechanisms that are organically linked and cooperated with each other, namely, the public performance market construction mechanism, budget preparation mechanism, procurement execution mechanism, supervision and restraint mechanism.

\section{A. Construction Mechanism of Public Performance Market}

The construction mechanism of public performance market refers to the local government's establishment of a system that can effectively guide more social performance agencies to participate in the competition through legal, economic, 
administrative and other means, and has clear access threshold and clear rules [4].

The local government shall organize the cultural and industrial and commercial departments to formulate work plans, set up special groups, conduct a comprehensive field survey of all local theatrical performance teams, and make detailed statistics on their personnel structure, talent reserve, profitability and organizational capacity; The government procurement center and the industrial and commercial departments shall organize all performance agencies to register and file for the convenience of future government procurement; The local cultural department will conduct a comprehensive survey of the preservation of local intangible heritage such as folk arts and performances, and will focus on the investigation of the troupes where outstanding stage artists are located.; Local leading departments organize experts and special teams to judge the local cultural and entertainment market and cultural resources, measure the maturity of the local cultural and entertainment performance market. The second is to establish the entry threshold. With the assistance of local cultural departments, the procurement center has formulated admission standards to exclude arts and cultural troupes with low qualifications; According to the Procurement Law of the People's Republic of China, the local government may authorize social intermediary organizations (law firms, etc.) to engage in bidding agency business, and shall set corresponding entry thresholds; According to the relevant provisions of the government procurement regulations, the local government should relax the regional restrictions on other regions and all kinds of private excellent performance resource suppliers, and shall not discriminate against suppliers.

\section{B. Budget preparation mechanism}

The budgeting mechanism refers to the processing system in which local departments and units (mainly financial departments and cultural departments) formulate annual plans for raising and distributing budget funds. When local governments in our country carry out budget preparation of public performance funds, the specific measures shall be in accordance with the "Government Procurement Law" and the "Regulations on the Implementation of the Procurement Law" [5]. First of all, the local civil affairs and cultural departments will investigate the richness of local residents' recreational life, grasp the residents' demand and preference for public performances, and on this basis, organize an expert committee to demonstrate the feasibility, risk control report and investment budget of the performance project.

Secondly, the local finance department shall issue the relevant documents and notices on departmental budget preparation, specifying the requirements for departmental budget preparation. As a specific fund user, the local cultural department should specify the name, type and content of the performance project to be purchased, the fund budget, etc. After the draft is prepared, it shall be submitted to the competent department for examination and approval and submitted to the finance department. Thirdly, the local finance department will review the performance service items submitted and their budgets, put forward suggestions for total amount adjustment and control indicators according to the fund situation, and issue them to the fund use department after reporting to the government at the same level for approval. [6].

\section{Procurement execution mechanism}

Procurement execution mechanism refers to the processing system in which local governments provide public performances by signing contracts with social performance agencies and paying financial funds. The "Government Procurement Law" and the "Regulations on the Implementation of the Procurement Law" is the general articles of association on which the mechanism operates. In addition, the Law on Tendering and Bidding, the Regulations on the Implementation of the Law on Tendering and Bidding, etc. also provide legal support for the procurement implementation of local governments.

According to the Guiding Opinions on Government Purchase of Services from Social Forces issued by the General Office of the State Council, there are many ways for the government to purchase public performances, including public bidding, competitive negotiation and cooperative purchase. Among them, bidding and purchasing mode, as the basic mode of contract outsourcing, is frequently used and has formed a relatively fixed and mature process mechanism through years of local government procurement practice. Article 26 of the government procurement law clearly stipulates that "public bidding shall be the main procurement method for government procurement."

\section{Supervision and restraint mechanism}

This mechanism refers to the system in which the local government, through tracking and supervising the budget preparation and procurement execution, conducts accountability investigation on the illegal operation and lagging work of various subjects (including the government and suppliers). The mechanism is composed of internal and external supervision systems, and is currently dominated by internal supervision systems. The internal supervision system includes functional department supervision, general supervision and supervisor supervision. The supervision of functional departments mainly refers to the local cultural departments as the use units of funds, which are responsible for regularly inspecting the rehearsal progress, site props, firefighting facilities, etc. of the undertaking troupe. Local supervision and auditing departments are responsible for formulating internal auditing systems and plans, and auditing and supervising the purchasing activities of cultural departments. The local procurement center is responsible for supervising the performance supplier's project completion progress; As the core of the internal supervision system, the local finance department is responsible for controlling the use of the purchase funds throughout the process. At the same time, it should also ensure the operation of funds and investigate and deal with illegal interception through copying and consulting relevant documents. General supervision means that governments at all levels carry out supervision between higher and lower levels according to hierarchical subordination. The specific forms include supervision, guidance, criticism, suggestions and punishment by the local government at a higher level for the work of various functional departments. 
Regular reports of each functional department to the superior government; Joint investigations and special group investigations organized by local governments at higher levels.

\section{THE REALISTIC DILEMMA OF LOCAL GOVERNMENT PurChasing Public PERFormanCE}

\section{A. Insufficient purchase scale}

First, the total amount of funds invested is insufficient. Although the total expenditure of cultural and sports media has been increasing in recent years, its proportion in the national financial expenditure is relatively low. According to the data released by the Ministry of Culture in 2017, the national expenditure on cultural and sports media is 336.7 billion Yuan, accounting for only $1.66 \%$ of the total public budget expenditure. Among them, the expenditure on artistic performance is even less, only 597 million Yuan. In addition, the average annual growth rate of cultural and sports media expenditures is the lowest among all financial expenditures (6.4\%), which is obviously behind other financial expenditures.

Second, the sources of funding for public performances are fragmented. Local governments purchase public performances from a variety of sources, including budget funds, special business funds, extra-budgetary funds, welfare funds, etc., which perplexes the continuity of purchase policies. For example, in some areas, public performances belong to the category of social services purchased by the government, and their expenses are paid by the welfare fund at the municipal level, while at the district level, they are matched by relevant government budget funds. The reason is that most local governments have not fully incorporated the funds for purchasing public performances into the public finance system and have not included public performances in the regular annual purchase plan.

\section{B. Lack of market supply and competitiveness}

First of all, the public performance market is small in scale and insufficient in supply. At present, China's nongovernmental theatrical performance market is in the initial stage of development. Some non-governmental troupes are still weak in their professional ability, and their artistic level and organizational ability cannot meet the specified requirements and they cannot undertake large-scale public performances. Therefore, the main undertaking body of public performance business is still a few experienced public (state-owned or provincial troupes) theatrical troupes. Secondly, the public performance market is not competitive enough. At present, the complicated interest relationship between public troupes and local governments often leads to the fragmentation of the public performance market. On the surface, some local governments carry out public bidding, but in essence, they set some relatively strict requirements for admission.

\section{Lack of policies and regulations}

First, the procurement boundaries and contents of public performances are vague. Although the current "Government Procurement Law" and "Regulations on the Implementation of the Procurement Law" recognize the legitimacy of public service procurement, in many central guiding regulations (such as the "Classification Table of Government Procurement Items" issued by the Ministry of Finance), service items are mostly logistics services for administrative departments, and most public services including public performances are not included in the catalog. In addition, although some places have drawn up purchase boundaries for public services, most of the standard-setting bodies have lower levels (mainly county and district governments) and lack authority. Therefore, the specific content and service boundaries of public performances are not clear, which brings legal basis troubles when local governments make budgets, annual final accounts and match funds. Second, the right to purchase public performances is relatively vague. According to the Government Procurement Law, local governments will publish this year's government centralized procurement catalog at the beginning of each year. All general procurement items listed in the government centralized procurement catalog must enter a unified procurement center for centralized procurement.

\section{Irregularities in the purchasing process}

First of all, there are some irregularities in the budget compilation of local governments when purchasing public performances. The local government's budget for purchasing public performances has only a "soft constraint" effect on the cultural department, with frequent additional funds, and the performance purchasing activities are not carried out as planned. Secondly, many local governments have complicated administrative approval procedures. This has brought greater time and round-trip costs to the hospital group that is planning to bid. For example, according to the requirements of some local financial departments, suppliers participating in the bidding negotiations need to register with the procurement management office in advance to be eligible for procurement documents. However, ordinary hospital groups are less likely to be successful in one registration, and the cost of multiple round trips is too high. This will virtually exclude some small non-local hospital groups from the competition. Third; the government's purchase of public performance contracts is not standardized. Article 47 of the "Regulations on the Implementation of the Procurement Law" stipulates that the standard text of the government procurement contract must be adopted to clarify the rights and obligations of the parties to the procurement. However, when signing the contract, the accepting hospital group is often in a weak position. Many local procurement centers do not emphasize the rights and interests of the hospital group in the contract model.

\section{E. Deficiencies in the professional and technical capabilities of local governments}

First, there are deficiencies in technical methods in previous research. Local governments need to grasp the richness and demand of people's recreational life before purchasing public performances, but the economic development, population structure and folk culture of each place are different and complicated, and there is no fixed statistical caliber and workflow. How to collect the opinions of the residents in the area is difficult in terms of methods. 
Second, the overall planning capacity for budgeting is insufficient. Although the Budget Law of the People's Republic of China clearly stipulates that financial departments at all levels shall be responsible for preparing drafts of budgets and final accounts at the corresponding levels, due to the disunity of budget power in practice, and the multiple values of public performances, it is difficult to implement a unified budget policy, and local governments have difficulties in determining the number, type and specific content of performances. In addition, the particularity of public performance products requires that the bidding personnel must not only have the basic abilities of expression and communication, organization and coordination, but also have certain artistic appreciation ability and certain professional knowledge ability in formulating the pricing principles of public performance projects and the selection of supply organizations. At present, there are also deficiencies.

\section{SUGGESTIONS AND MEASURES}

\section{A. Enhancing local financial security}

First of all, local finance should increase investment in this area through multiple channels and at multiple levels to enhance its security. Public performances will be included in the local government's annual routine procurement plan, and the budget amount will be appropriately increased according to local conditions. Secondly, the financial benefits of funds should be improved through diversified subsidy programs. Subsidies can be given to suppliers of public performances, such as on-site rental subsidies to troupes where outstanding stage artists are located and troupes of outstanding traditional folk arts. Residents can be subsidized in purchasing tickets, such as quantitative subsidies for low-priced tickets sold for specific commercial performances, so that more viewers can have the opportunity to watch excellent performances. Secondly, in view of the fragmentation of funding sources for public performances, local governments need to improve the budgeting system as soon as possible. Local governments should establish a standard system of expenditure for purchasing public performances as soon as possible. In addition to financial revenue funds, social funds retained by local government departments, such as lottery public welfare funds and special public welfare funds, should also be managed on a budget basis. Only by properly budgeting at the source can the problem of fragmentation of public performance purchase funds be fundamentally solved.

\section{B. Improving the "quasi-market" construction of public performance}

Local governments should establish a "quasi-market" with diversified public performance providers, fair competition and equal legal obligations for buyers and sellers.

First of all, in order to make the competition in the public performance market fairer, the establishment and review process of the local government's admission qualification for the troupe should be clarified in the form of legal provisions. Local governments can relax some unnecessary conditions and guide them to standardize their own construction.
Secondly, we should focus on solving the problem of market segmentation. For projects subject to public bidding, a unified bidding platform should be determined in accordance with the local procurement process, so that high-quality private hospital groups outside the region can also participate in the competition, and black-box operations and local protectionism can be eliminated. At the same time, in the choice of purchasing mode, local governments should try their best to use the mode of public bidding. Article 11 of the Government Procurement Law clearly stipulates that "government procurement information shall be released to the public in a timely manner on the media designated by the government procurement supervision and management department". If you need to choose other modes (such as directional entrustment) under special circumstances, you should first publicize them to the public for comments.

\section{Absence of Amendment Regulations}

First of all, we must gradually clarify the procurement boundaries and contents of public performances. The Ministry of Finance and the Ministry of Culture shall specify in the guidance documents the service categories, coverage principles, supply levels, financial sources, etc. of public performances. At the same time, local governments also need to actively explore the specific boundaries of the central government at the local level. Local governments should adhere to the procurement reform direction of "centralized procurement is the main, decentralized procurement is the auxiliary", further improve the concentration of government procurement, minimize the proportion of public performances purchased by the Ministry of Culture, and truly control the chaotic situation of decentralized procurement and multiple government departments at the source.

\section{CONCLUSION}

In specific purchase activity, especially when faced with different areas and different cultures, the local government should combine the actual analysis with evaluation under this analysis framework, and then to determine the optimal operation mechanism suitable for the local, in which way can the local government maximize the release of the government purchase of public cultural service system of value, and maximize the supply of public cultural service quality and service efficiency.

\section{REFERENCES}

[1] National Bureau of Statistics of the People's Republic of China. China statistical yearbook [M]. Beijing: China statistics press, 2017.(I Chinese)

[2] National considerable for Humanities. Information about the policies that government your both grant or cooperative agreement [EB/OL] https://www.neh.gov/grants/manage, 2019-4-12.

[3] Culture and tourism department. The law of the People's Republic of China on culture and tourism statistics bulletin of the cultura development in 2017 [EB/OL].

http://zwgk.mct.gov.cn/auto255/201805/t20180531_833078.html, 201805-31/2018-05-31.

[4] Wang Yanhong. The operation mode of public service contract outsourcing: competition, negotiation and internal and external system outsourcing [J]. Social science front,2013(03):207-210.(I Chinese) 
[5] Ge Daoshun. Public service procurement in China: from administrationdriven to law-based governance [J]. Journal of national academy of administration, 2017 (03) : 65-70.(I Chinese)
[6] Han Lingli. Research on the legal issues of "soft constraint" of China's fiscal budget [D]. Central south university, 2013.(I Chinese) 